\title{
Development and Research of Intelligent PID Controller Based on Fuzzy Neural Network
}

\author{
Xu Qiuhua*
}

\author{
Zhoukou Vocational College of Science and Technology, China
}

\begin{abstract}
In this paper, intelligent fuzzy control theory is introduced in the model of neural network algorithm, and the neural network system is improved by the PID controller, which has realized the feedback and adjustment function of neural network system, and has made the reaction of the system be more accurate and stable. In order to verify the validity and reliability of the designed intelligent control PID algorithm based on the fuzzy neural network in this paper, the algorithm is carried on the programming by using Matlab programming software, and the control process of PID is calculated by NNbox simulation toolbox, at last, it has obtained the curve of PID control response changing over time. From the response curve, it can be seen that after the PID proportional coefficient is regulated by using fuzzy neural network intelligent control algorithm, it can quickly and steadily obtain the control curve, which has realized better intelligent control effect, and has provided technical reference for the research of intelligent PID controller.
\end{abstract}

Keywords: PID controller, fuzzy control, neural network, Matlab software, NNbox toolbox.

\section{INTRODUCTION}

At present, BP neural network algorithm is one of the most widely used artificial neural network method, and it has strong learning function, self-organizing function, adaptability and nonlinear mapping ability, which can be approximate to arbitrary precision of many functions. In recent years, in order to solve the problem of convergence speed and convergence time of BP neural network, many experts and scholars have provided relevant improving approaches. NNbox neural network toolbox of Matlab provides conditions for solving this problem. The toolbox contains a series of functions of neural network from the establishment to the training and to the simulation, and it can conveniently design the neural network algorithm by changing the training function. It also can be improved on the basis of the provided functions by NNbox. In the paper, neural network system has been improved by using the fuzzy intelligent control algorithm, and it has obtained better PID control effect.

\section{THE FUZZY NEURAL NETWORK METHOD OF INTELLIGENT PID CONTROLLER}

In the process of neural network system information transfer, if the neural network has no back propagation network, after the signal has through the neurons, the process of information transfer is over. And in this paper, the use of fuzzy intelligent control algorithm has achieved the frontfeedback process of neural system network. For this kind of combined neural network system with each other, the signal is continuously adjusted through the feedback from the initial state, eventually, it achieves to be the balanced state. For the adjustment of balanced state, this paper mainly uses PID controller to achieve it.

Fig. (1) shows the structure diagram of the fuzzy neural network intelligent control PID algorithm designed in this paper. In the process of information transfer, network is always in the state with constantly changing and adjustment. And the use of feedback information makes the response of neural network system be more accurate, at the same time, the use of PID adjustment can make the response of neural network system be more stable.

\section{THE DESIGN OF FUZZY NEURAL NETWORK IN- TELLIGENT CONTROL ALGORITHM}

Fuzzy control process mainly has three variables, including the basic domain of the training samples, the basic domain of training residual, and the output variable of brake control, and the three variables can be written as the form of discrete formulas, so it is as shown in the formula (1).

$y=\left[\frac{2 n}{b-a}\left(x-\frac{a+b}{2}\right)\right]$

Where $x \in[a, b], \mathrm{n}$ represents the dispersion. Neural network system is a biological output process. Generally, it is a model with multi-input and single-output, and it is as shown in Fig. (2).

Assuming that when the input variable of neurons is said to be $x_{i}(i=1,2 \ldots, m)$, and the output is said to be $y_{j}$, then the relationship between the input variables and the output variables can be expressed as shown in formula (2). 


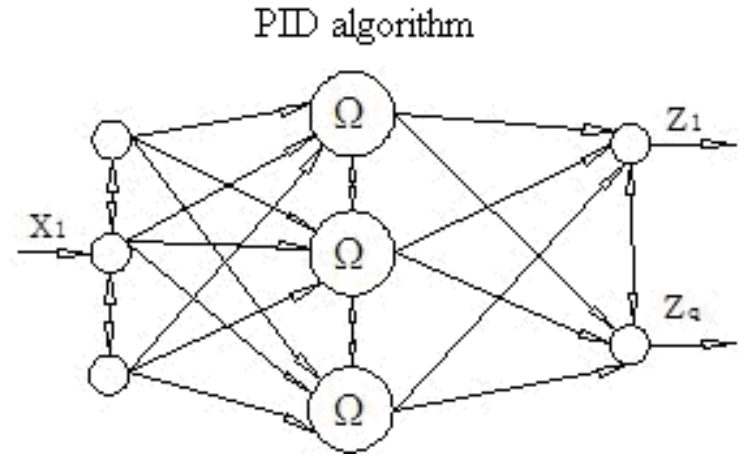

Fig. (1). Structure diagram of fuzzy neural network intelligent control PID algorithm.

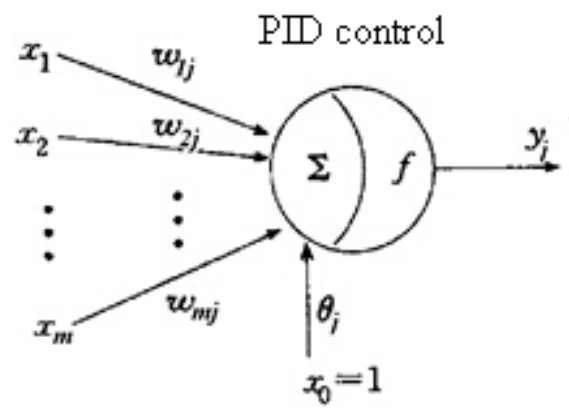

Fig. (2). Schematic diagram of the neural network information transfer.

$$
\left\{\begin{array}{c}
s_{j}=\sum_{i=1}^{m} w_{i j} x_{i}-\theta_{j} \\
y_{j}=f\left(s_{j}\right)
\end{array}\right.
$$

Where, $j$ represents the threshold, $W_{i j}$ represents the connected weighting factor from the neuron $i$ to the neuron $j, f()$ represents the fuzzy control function, then the membership function can be expressed as shown in the formula (3).

$$
\mathrm{u}_{\mathrm{E} \wedge \mathrm{EC} \wedge \mathrm{U}}=\left\{\begin{array}{c}
g(x,-5,-1) \\
\operatorname{trig}(x,-3,-2,0) \\
\operatorname{trig}(x,-3,-1,1) \\
\operatorname{trig}(x,-2,0,2) \\
\operatorname{trig}(x,-1,1,3) \\
\operatorname{trig}(x, 0,2,3) \\
g(x, 1,5)
\end{array}\right.
$$

It can solve the fuzzy control function with the weighted average method.

$$
u=\frac{\sum_{i=0}^{21} u\left(z_{i j}\right) z_{j}}{\sum_{i=0}^{21} u\left(z_{i j}\right)}(i=j=1,2, \cdots, 21)
$$

Where, $u$ represents the value adjusted by the neural network feedback, and the form of PID control can be written as shown in the formula (4).

$$
\begin{aligned}
& u(k)=u(k-1)+\left(k_{p}+k_{i}+k_{d}\right) e(k) \\
& +\left(-k_{p}-2 k_{d}\right) e(k-1)+k_{d} e(k-2)
\end{aligned}
$$

It only needs to set up three parameters of $k_{p}, k_{i}$ and $k_{d}$ , so as to achieve the process of fuzzy intelligent control. In order to realize the fuzzy intelligent control function of fuzzy neural network algorithm, this paper uses Matlab software to carry on the programming of this algorithm. Firstly, it carries on the defuzzification design of the intelligent control for the neural network algorithm, and the used main program is shown as following.

$$
\begin{aligned}
& \text { V_R1=dikaer(E_R,7,EC_R,7); } \\
& \text { V_R1=reshape(V_R1,1,49); } \\
& \text { V_R2=jdikaer(V_R1,49,R,7); } \\
& \text { V_R=max(V_R2); } \\
& \text { V_L=mean(V_R); }
\end{aligned}
$$

Intelligent control selection rules and procedures are as follows.

brake $=-$ flisan $\left(-150,150,3, \mathrm{u} \_\right.$L);

$\mathrm{k} \_2=\mathrm{k} \_1$;

$\mathrm{k} \_1=\mathrm{k}$; 
Table 1. Fuzzy control rules.

\begin{tabular}{|c|c|c|c|c|c|c|c|c|}
\hline & $\mathbf{- 3}$ & $\mathbf{- 2}$ & $\mathbf{- 1}$ & $\mathbf{0}$ & $\mathbf{1}$ & $\mathbf{2}$ & $\mathbf{3}$ & 0 \\
\hline \hline NB & 1 & 0.5 & 0 & 0 & 0 & 0 & 0 \\
\hline NM & 0 & 1 & 0.5 & 0 & 0 & 0 & 0 \\
\hline NS & 0 & 0.5 & 1 & 0.5 & 0 & 0 & 0 \\
\hline ZO & 0 & 0 & 0.5 & 1 & 0.5 & 0 & A2 \\
\hline PS & 0 & 0 & 0 & 0.5 & 1 & 0.5 & 0 \\
\hline PM & 0 & 0 & 0 & 0 & 0.5 & 1 & 0 \\
\hline PB & 0 & 0 & 0 & 0 & 0 & 0.5 & 1 \\
\hline
\end{tabular}

Table 2. Comparison of different neural network algorithm results.

\begin{tabular}{|c|c|c|c|}
\hline Algorithm & Training Function & The Number of Training & Mean Squared Error \\
\hline \hline Genetic algorithm & traingd & 2000 & 0.134968 \\
\hline Neural network algorithm & traingdm & 2000 & 0.108883 \\
\hline Fuzzy neural network algorithm & trainrp & 2000 & 0.0135652 \\
\hline
\end{tabular}

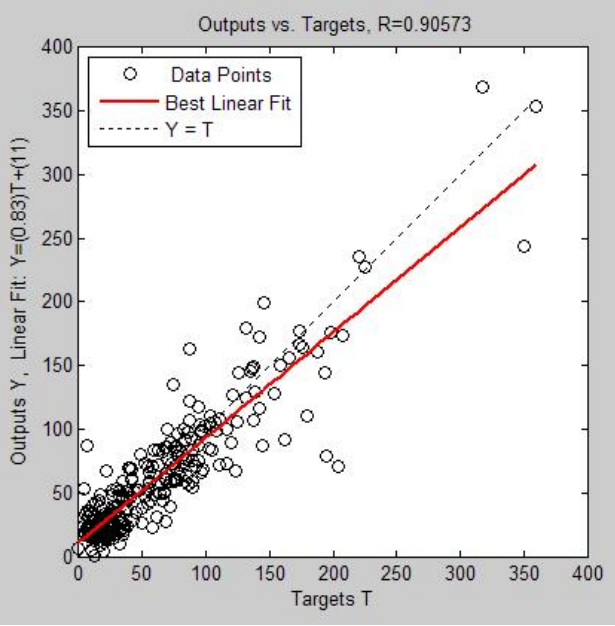

Fig. (3). Linear regression analysis.

if $(\mathrm{k}<0)$

if $((\mathrm{k}>$-Eswith $) \|($ throttle_1 $=0))$

if(throttle $<=$ throttle_1)

throttle_1=throttle;

$\mathrm{v}=$ throttle;

$\mathrm{Q}(\mathrm{k})=\mathrm{v}$;

$\mathrm{W}(\mathrm{k})=0$;

Else

\section{COMPUTER VALIDATION OF THE FUZZY NEU- RAL NETWORK PID ALGORITHM}

In order to validate the validity and reliability of fuzzy neural network PID control algorithm designed in the second parts, this paper uses the Nnbox neural network toolbox of Matlab to simulate the algorithm. Firstly, it builds the fuzzy control rules, as shown in Table $\mathbf{1}$.

As shown in Table 2, the analog output is the fuzzy vector of $1 \times 7$, and the corresponded discrete variable of each row element is $z$. Through the training of neural network training samples, finally it obtains the linear regression analysis results, as shown in Fig. (3). 


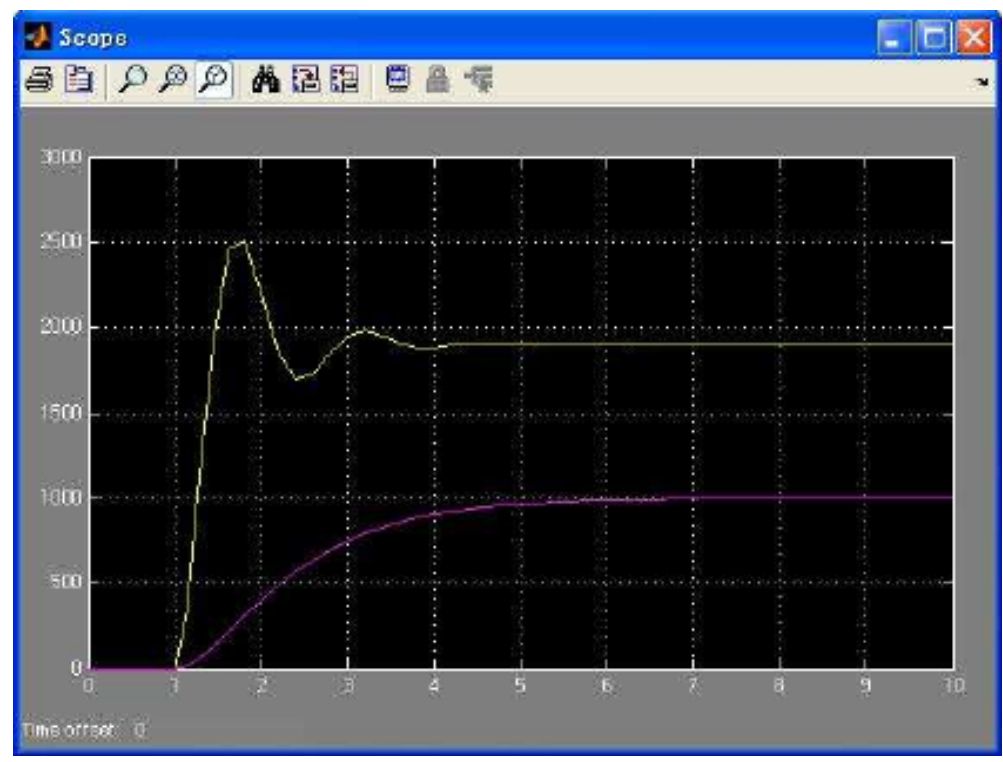

Fig. (4). PID intelligent adjustment process.

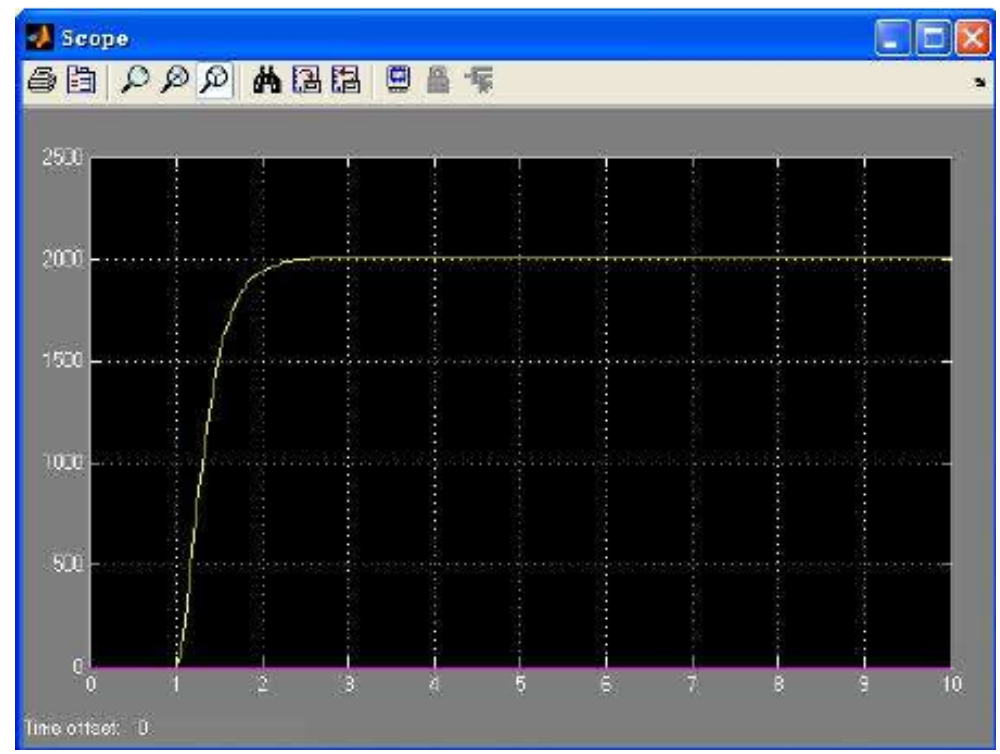

Fig. (5). PID controller intelligent optimization and adjustment process.

As shown in Fig. (3), it represents a linear regression analysis process of the neural network training samples. All data are placed in a data set, and these data include the training data, validating data and test data. At last, the linear regression results are output.

Fig. (4) shows the schematic diagram before the adjustment of fuzzy neural network on PID. Firstly, the integral item and differential item are removed, the systems control mode becomes the pure proportional control mode. It can be seen from the simulation model that when the proportional adjustment coefficient of the system is larger, the system will response rapidly, but the reaction of the system is not stable, so it needs to be optimized and regulated.
Fig. (5) shows the output curve of intelligent adjustment on PID controller by using fuzzy neural network algorithm. From the simulation results, it can be seen that after the adjustment of fuzzy neural network, the response of system is quick, and the run is smooth.

Fig. (6) shows the actual precise control process and the results of automation fuzzy intelligent control process. The image on the left shows the non-fuzzy intelligent control results, and the image on the right shows the fuzzy intelligent control results. Through the comparison, it can be seen that the fuzzy intelligent control can achieve precise control effect. 

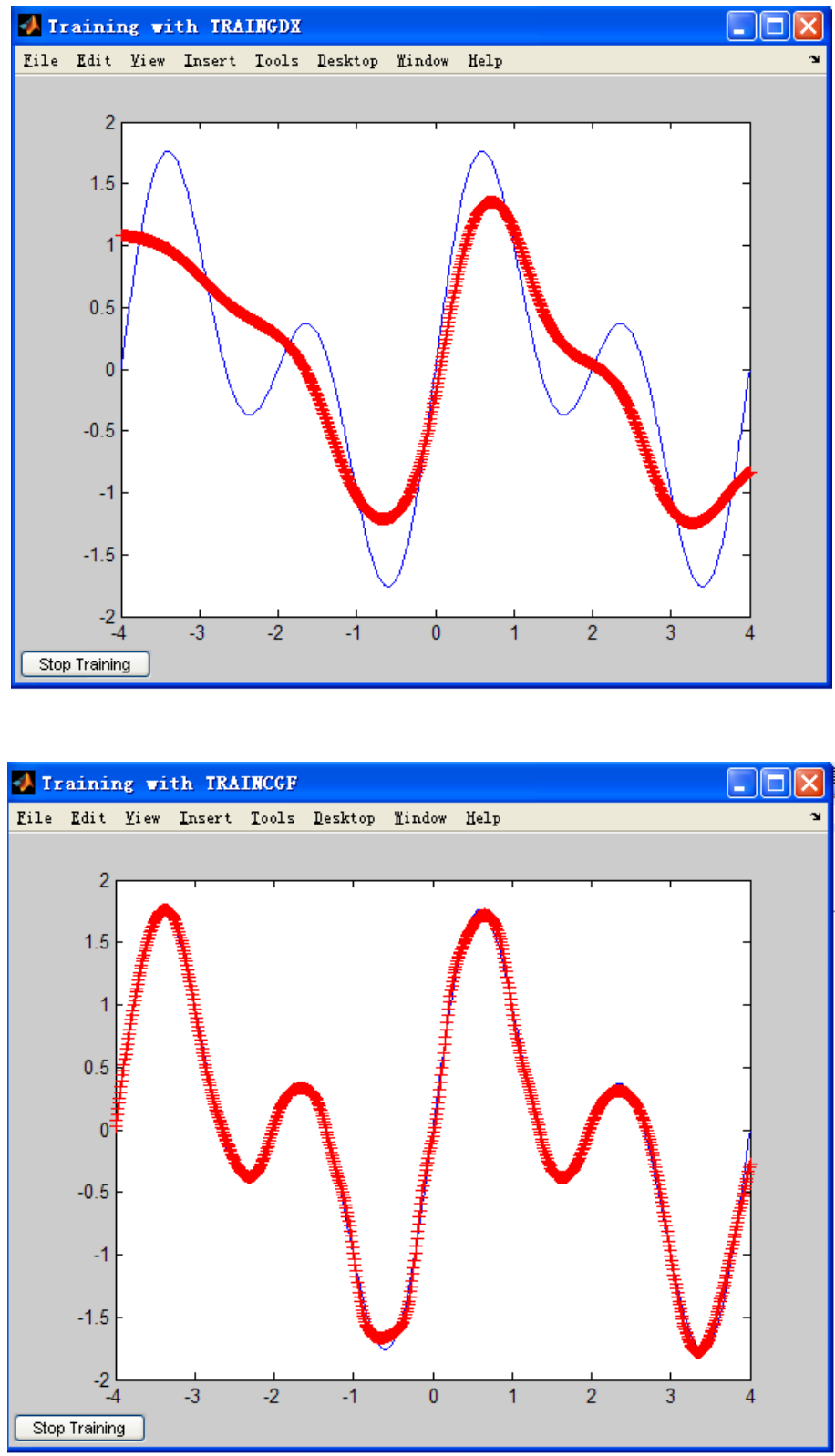

Fig. (6). The final results of intelligent control.

From the results, it can be seen that with the same number of training, the calculation error caused by fuzzy neural network control algorithm is lower than that of the genetic algorithm and neural network algorithm, and fuzzy neural network control algorithm has a high control accuracy.

\section{CONCLUSION}

This paper established the mathematical model of fuzzy neural network PID intelligent control, and the frontfeedback function of neural network was used to realize the regulating function of proportional coefficient, which made the adjustment of the system be more stable.Using Matlab programming to verify the algorithm, and using NNbox toolbox to carry out the numerical simulation on neural network algorithm, then it obtained the response curve of PID control with changing over time.

Through the comparison between the curve of PID control with changing over time and the different neural network algorithm, it could be seen that the fuzzy neural network could quickly adjust the control process, and it had achieved a better control effect.

\section{CONFLICT OF INTEREST}

The authors confirm that this article content has no conflicts of interest. 


\section{ACKNOWLEDGEMENTS}

Declared none.

\section{REFERENCES}

Dan Xu, Guodong Wang, Binggang Cao, Xiaohui Feng. Study on optimization torque distribution strategy for independent 4WD electric vehicle. Journal of Xi'an Jiao Tong University, Vol. 46 (3), (2012), p.1-5.

[2] Guofei Li, Yi Lin, Hongwen He. Regenerative braking control strategy for electric vehicle. Transactions of Beijing Institute of Technology, Vol. 29 (6), (2009), p.520-524.

[3] Youqun Zhao, Fen Lin. Vehicle state estimation based on UKF algorithm. China mechanical engineering, Vol. 21 (5), (2010), p. a615-619,629

[4] Haitao Ding, Konghui Guo, Fei Li, et al. Arbitrary path and speed following driver model based on vehicle acceleration feedback . Journal of mechanical engineering, Vol. 5(10), (2010), p. 116-120.

[5] Changfu Zong, Jingwen Liu, Hongyu Zheng, et al. Modeling and special condition simulation of electric vehicle with 4WID/4WIS. Automotive engineering, Vol. 33 (10), (2011), p.829-833.
[6] Lei Zhou, Yugong Luo, et al. Braking control of electric vehicles while coordinating regenerative and anti-lock brakes. Journal of Tsinghua University, vol. 5 (49), (2009), p.728-732.

[7] Jiejia Li, Hao Chen, Ying Li. Application of neural network decoupling control in central air-conditioning system. Journal of Shenyang Jianzhu University, Vol. 28 (1),(2012), p.182-186.

[8] Hongxin Li, Jianzhong Yang. An approach of cooling coils modeling based on two parameters. Building energy \& environment, vol. 28 (6), (2009), p.15-17.

[9] Qingshan Meng. Discussion of optimum energy-saving of water source heat pump with variable flow water system . Refrigeration and air-conditioning, vol. 10 (01), (2010), p.84-89.

[10] Duogen Hu. Research on parameter adjustable fuzzy control in chilled water system of air condition based on prediction. Hefei: Hefei University of Technology, (2010).

[11] Aifeng $\mathrm{Hu}$. Analysis of heat transfer on radial heat-pipe without wick and the calculation of heat transfer coefficient. Science and technology information, 2008, vol. 2 (5): 5-6.

[12] Desbourough L, Miller R, Increasing Customer Value of Industrial Control Performance Monitoring-Honeywell's Experience, AIChE Symposium Series, vol. 98(326), (2002), p.153-186

[13] M.I. Hasan, A.A. Rageb, M. Yaghoubi, H. Homayoni, Influence of channel geometry on the performance of a counterflow microchannel heat exchanger, Int. J. Therm. Sci. vol. 48 ,(2009) 1607-1618.

(C) Xu Qiuhua; Licensee Bentham Open.

This is an open access article licensed under the terms of the Creative Commons Attribution Non-Commercial License (http://creativecommons.org/licenses/by-nc/3.0/) which permits unrestricted, non-commercial use, distribution and reproduction in any medium, provided the work is properly cited. 